\title{
Design of Application Schema and Feature Catalogue for Marine Casualty Based on S-100
}

\author{
Hyoseung $\mathrm{Kim}^{1}$, ChangHo Mun ${ }^{2}$ and Seojeong Lee* \\ ${ }^{1}$ Department of Computer Engineering Korea Maritime and Ocean University \\ Busan, Korea \\ ${ }^{2}$ Department of Computer Engineering Korea Maritime and Ocean University \\ Busan, Korea \\ *Division of Marine Information Technology Korea Maritime and Ocean \\ University Busan, Korea \\ ${ }^{1}$ khs9962@gamil.com, ${ }^{2}$ ckdewq10@naver.com,*sjlee@kmou.ac.kr
}

\begin{abstract}
According to the development of IMO e-Navigation, the increase of marine data and software based services are highly anticipated. Relevant standards are demanded to be prepared alongside e-navigation. IHO defined the S-100 standard in order to represent different spatial-geographic information. On the basis of S-100, some product specifications are tested to be defined for electronic navigational chart, bathymetric surface, tidal information, dynamic water level, etc. This paper tries to describe the main part of a product specification for maritime casualty based on the S-100 standard. It performs the data modeling to derive features, information, and attribute types and defines the application schema and feature catalogue.
\end{abstract}

Keywords: S-100, specifications, application schema, feature catalogue, data modeling

\section{Introduction}

The e-Navigation strategy, promoted by the International Maritime Organization (IMO), is a system to combine and unify collections, integrations, communication, representations, and analyses of ship and land information related to sailing for safe navigation and marine environment protection [1]. The e-Navigation strategy will accelerate the introduction of equipment and technologies and the related definitions of international standards have been developed. The International Hydrographic Organization (IHO) defined the S-100 standard to represent the geographic data of electronic navigation chart systems. The S-100 standard helps in overcoming the restrictions and limitations of existing hydrographic data communication standards; S-57 so that different marine data can be integrated and utilized. In addition, it makes efforts to develop S-10x data specifications for different marine data including electronic navigation charts, bathymetry data and so on. The data specification as a part of S-100 product specification includes the model, application model, metadata, and encoding rules for the corresponding date on the basis of the data model of S-100 standards [2]. Currently, S101 has been completed which is for the electronic navigation chart data and S-102 for the bathymetry data. Different product specifications are either in development or the planning stages for factors such as sub-surface navigation (S-103), tides (S-104), and marine protected area (S-122) [3].

This paper provides a data model of product specification for maritime casualty according to the S-100 data specifications. Marine casualty includes a particular type, location and size of damage of accidents to support and assist safe ship navigations. The

* Corresponding Author 
result of this paper can be utilized to implement various types of marine safety related service as combining with other S-100 based product specifications.

\section{Related Research}

\subsection{E-Navigation and CMDS}

The IMO Maritime Safety Committee (MSC), decided to establish and introduce the eNavigation strategy by combining navigation technology and ICT to prevent maritime casualties caused by human factors [1]. To achieve the concept of e-Navigation appropriately, dealing with data must be implemented and operated using common structures.

IMO, IHO, and International Association of Lighthouse Authorities (IALA) have all made efforts towards standard data modeling as they became aware of its necessity as an e-Navigation strategy [4]. S-100 has been developed to display the marine environment data, 3D spatial data, and other important data on the existing electronic navigation chart applying S-57. IMO decided to adopt S-100 as a Common Maritime Data Structure (CMDS) of e-navigation.

\subsection{Existing Researches on $\mathrm{S}-100$}

E-Navigation is a technical strategy for the automation and digitization of ships by combining electric-electronic systems with the ships' technology. With the e-Navigation strategy, different electric-electronic equipment will be equipped on the ships to collect and communicate different data. As the e-Navigation strategy implementation plan started to be shaped, there has been increasing demand for an integrated representation of different marine data. To this end, it was decided to use the IHO data communication standard, S-100, as the CMDS to communicate data.

The S-100 standard is a system to communicate, share, and use different marine data, as well as electronic navigation charts, by combining the existing electronic navigation chart communication standard, S-57, with the geographical information standard, ISO19100 series, so that the limited representations of different data are complemented and user requirements are reflected [5]. S-100 is a comprehensive guide for the representation of specifications. Many specifications have been developed on the basis of S-100, and here are the specifications developed or in development.

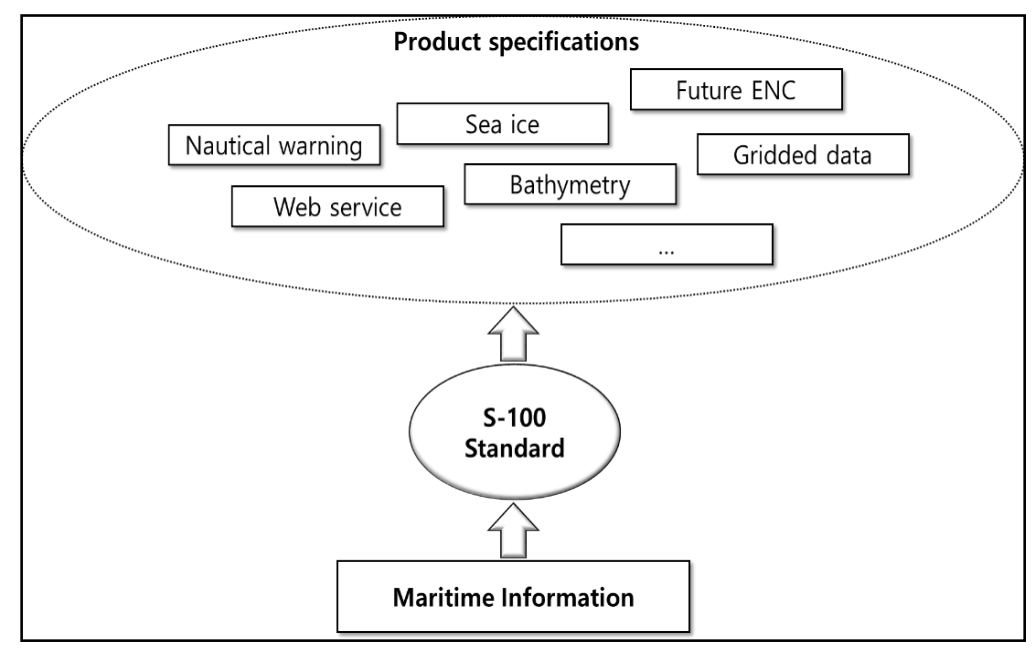

Figure 1. Concept of S-100 
Table 1. Product Specifications Being Developed by the IHO (Numbers S101 to 199$)$

\begin{tabular}{|c|l|}
\hline No. & \multicolumn{1}{|c|}{ Title } \\
\hline S-101 & Electronic Navigational Chart (ENC) \\
\hline S-102 & Bathymetric Surface \\
\hline S-103 & Sub-surface Navigation \\
\hline S-104 & Tidal product for surface navigation \\
\hline S-111 & Surface currents \\
\hline S-112 & Dynamic water level data \\
\hline S-121 & Maritime limits and boundaries \\
\hline S-122 & Marine Protected Areas \\
\hline S-123 & Radio Services \\
\hline S-124 & Navigational warnings \\
\hline S-125 & Navigational services \\
\hline S-126 & Physical Environment \\
\hline S-127 & Traffic Management \\
\hline S-128 & Catalogues of Nautical Products \\
\hline
\end{tabular}

Table 2. Product Specifications Being Developed by the IALA (Numbers S201 to 299)

\begin{tabular}{|c|l|}
\hline No. & \multicolumn{1}{|c|}{ Title } \\
\hline S-201 & Aid to Navigation Information \\
\hline S-210 & Inter-VTS Exchange format \\
\hline S-230 & Application Specific Messages \\
\hline S-240 & DGNSS Station Almanac \\
\hline S-245 & eLoran ASF Data \\
\hline S-246 & eLoran Station Almanac \\
\hline S-247 & Differential eLoran Reference Station Almanac \\
\hline
\end{tabular}

Table 3. Product Specifications Being Developed by other Organizations (Numbers from S-401)

\begin{tabular}{|c|l|}
\hline No. & \multicolumn{1}{|c|}{ Title } \\
\hline S-401 & Inland ENC \\
\hline S-411 & Sea Ice \\
\hline S-412 & Met-ocean forecasts \\
\hline
\end{tabular}

\section{Categorization}

IMO MEPC sub-committee has defined and recommended a form to report marine casualties and incidents [6]. The form identifies maritime casualties into 13 sorts of Collision, Grounding, Contact, Fire/explosion, Hull Failure, Loss of Control, Ship/equipment damage, Capsize/listing, Flooding/foundering, and Ship missing. This paper categorizes the accidents into 3 groups according to their characteristics. 
Table 4. Categorization about Maritime Casualty

\begin{tabular}{|c|c|c|}
\hline $\begin{array}{c}\text { Categorization in MSC- } \\
\text { MEPC }\end{array}$ & $\begin{array}{c}\text { Regrouped } \\
\text { Categorization }\end{array}$ & Being to be involved \\
\hline Collision & Collision & Ship \\
\hline Grounding & Grounding or & Geooranhic feature Facility \\
\hline Contact & Contact & Ueograpme Iedure, гасmіну \\
\hline Fire/explosion & \multirow{9}{*}{$\begin{array}{l}\text { Other type of } \\
\text { accidents }\end{array}$} & \multirow{9}{*}{$\begin{array}{l}\text { Depending on happening dependently to } \\
\text { another category or independently }\end{array}$} \\
\hline Hull failure & & \\
\hline Loss of control & & \\
\hline Ship/equipment damage & & \\
\hline Capsize/listing & & \\
\hline Flooding/foundering & & \\
\hline Ship missing & & \\
\hline Occupational accident & & \\
\hline Unknown & & \\
\hline
\end{tabular}

Table 4 shows the 'Collision', 'Grounding or Contact', and 'Other type of accidents.' 'Collision' is the group of accidents which have direct contacts with other ships. 'Grounding or Contact' is the group of accidents with ocean geographic features like rocks, and other things concerned with objects other than ships. 'Other type of accident' refers to accident with no subject or one that is caused by another accident.

\section{S-1xx PS Standardization, Application Schema, and Feature Catalogue Processes}

The S-100-based specifications are standardized in 6 steps given in Figure 2.

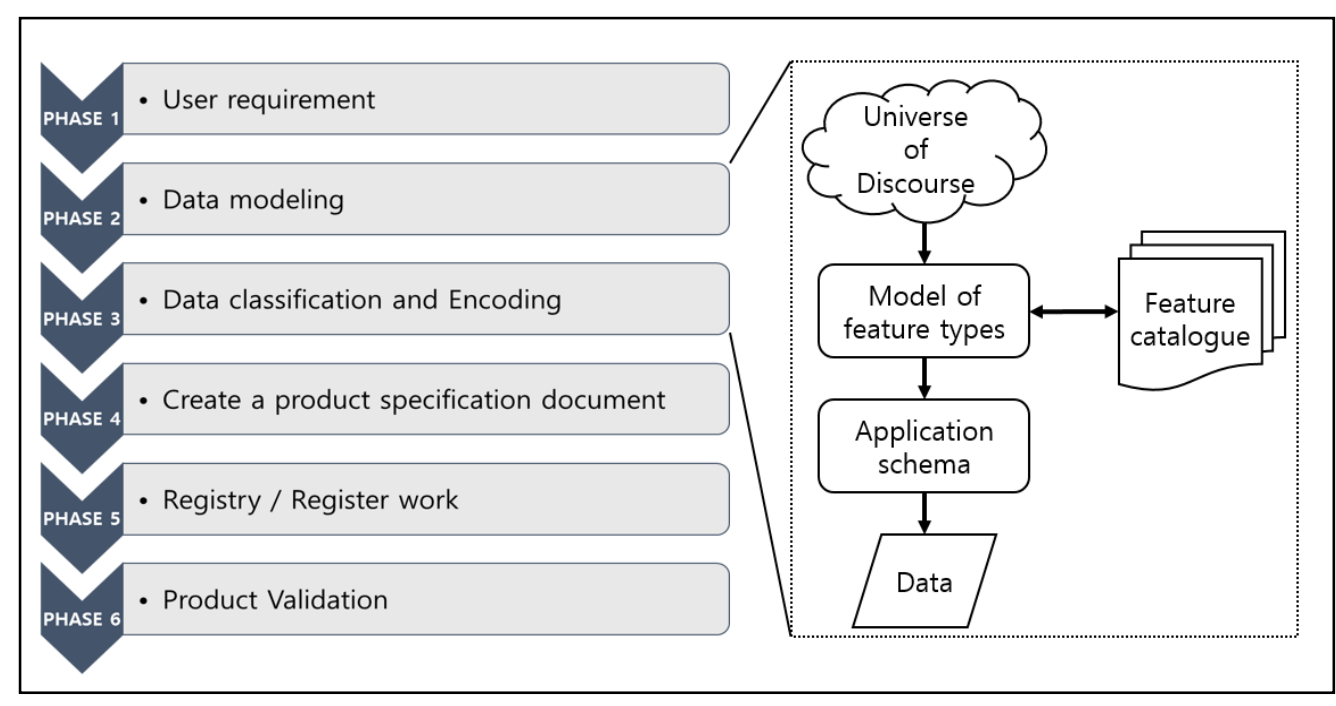

Figure 2. 6 Steps of S-100 Specifications

In the 1st step, the user requirements are analyzed. This step collects and analyzes the user requirements on the data or database. Based on the requirements, the step 2 models the data. In the S-100 standard, the data modeling is represented with the Unified Modeling Language (UML). The S-100 standard has been established by referring to the ISO19100 series in order to convert the real-world data into the geographical data model. The data modeling defines the real-world data as features and then summarizes them into the feature catalogue by referring to the data model conversion process defined by ISO19109. The application schema is developed with the feature information and then 
developed into an operable format, Geographic Markup Language (GML), through the encoding. After the encoding, it is arranged into the specifications of the document. The complete specifications document is registered into the registry of IHO and validated for standardization.

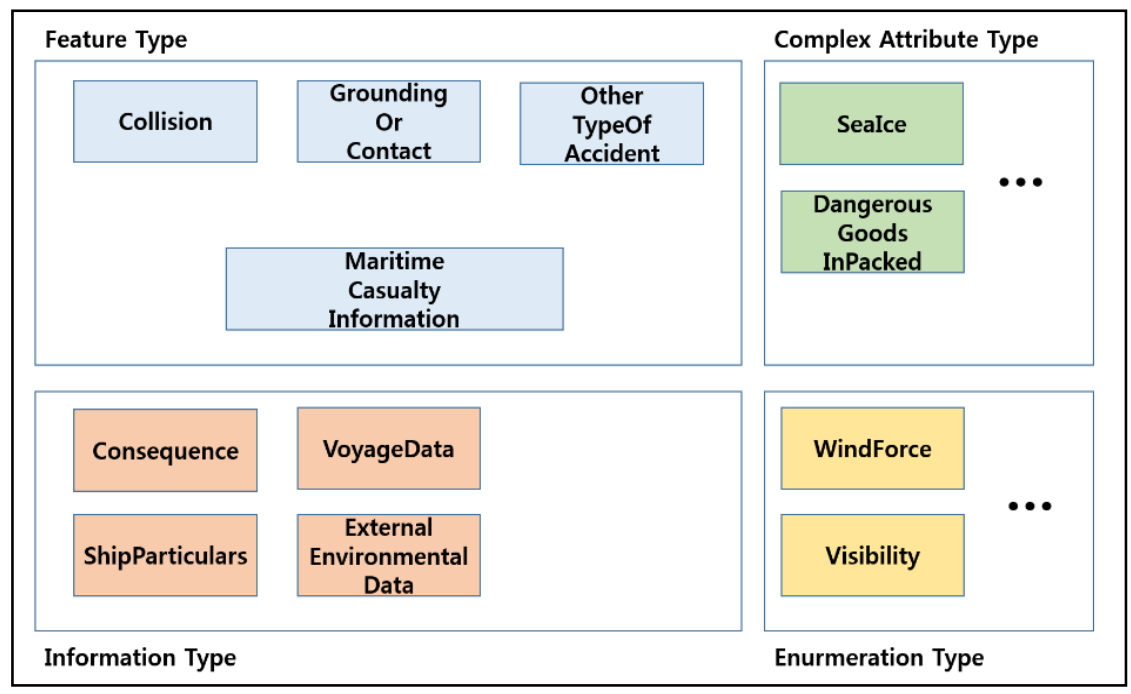

Figure 3. Overview of GFM Components

Figure 3 shows the results of the reduction of the entire UML. The S-100 standard uses the General Feature Model (GFM) to represent the concepts of feature model, property, and relationship. The feature refers to an abstract medium that represents a real phenomenon, and an accident case is the feature in this paper. There is an abstract feature type, 'MaritimeCasualtyInformation' and inheriting three kinds of categorized feature types, 'Collision', 'GroundingOrContact', and 'Other type of Accidents' of the categorization in Table 4. The 'Information' type is to represent related information, excluding spatial information by the definition of S-100 standard. Four kinds of information types can be defined with accident results, navigation data, ship data, and climate data for marine casualty of this paper.

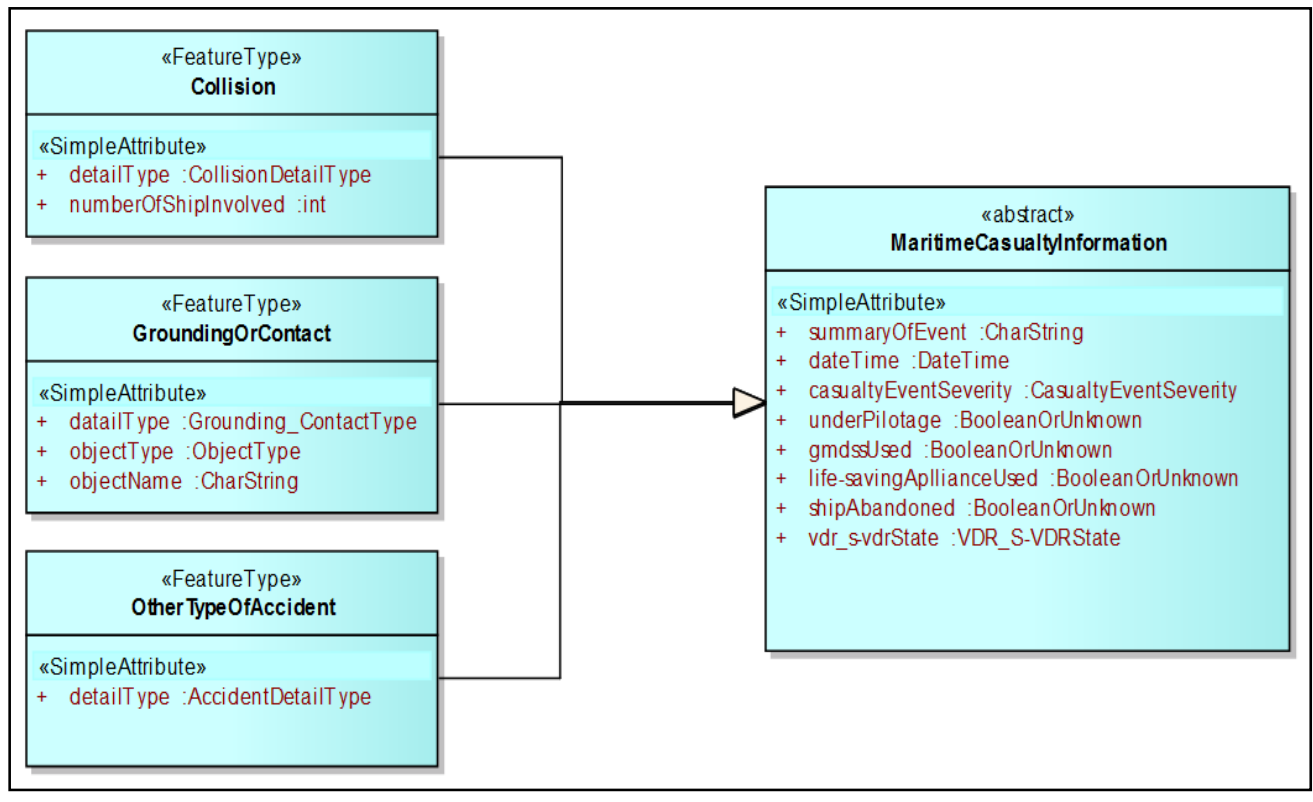

Figure 4. Relation and Attributes of Feature Type 
Figure 4 shows the relationship between 'Feature' types and attributes. An 'Abstract' type, 'MaritimeCasualtyInformation', includes common attributes for all of the three accident types. The 'Collision' type requires a sub category and the number of ships in the accident while the related ship data can be added through the 'ship particulars' according to the number of ships. The 'GroundingOrContact' includes a sub category and information on related objects; the 'objectType' to address the object type has attribute values pre-defined in the 'Enumeration' type.

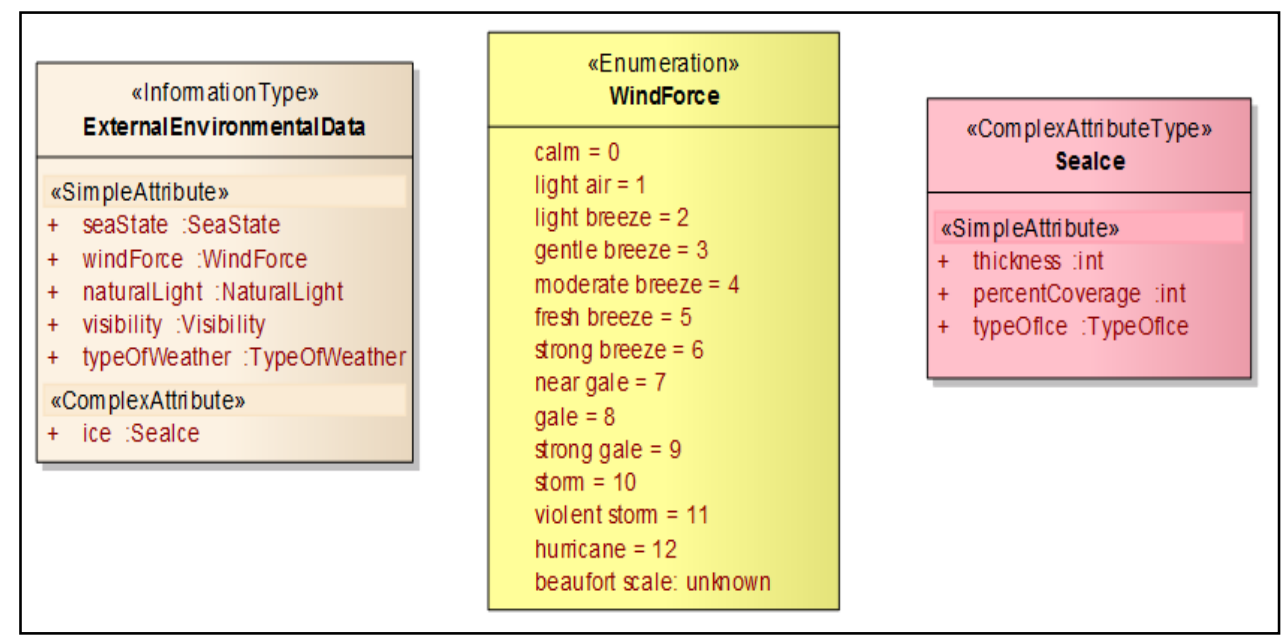

Figure 5. Example of Information, Enumeration, ComplexAttributeType

Figure 5 shows the examples of Information, Enumeration, and ComplexAttributeType types. The Information type, 'ExternalEnvironmentalData' is defined to include the accident, environment, and climate information, and the attributes were defined for the sea surface state, intensity of wind, and natural light. The intensity of wind is identified by the MSC-MPEC definition according to its degree as calm, light air, light breeze, gentle breeze, moderate breeze, fresh breeze, strong breeze, near gale, gale, strong gale, storm, violent storm, hurricane, and 'unknown'. The Enumeration type, 'WindForce', reflects this identification as attributes. For the attributes for sea ice a ComplexAttribute is used, named 'SeaIce', which indicates 'thickness', 'percentCoverage (scope)', and 'typeOfIce (type)'.

Table 5. Overall Components List

\begin{tabular}{|c|l|l|}
\hline \multicolumn{1}{|c|}{ Type } & \multicolumn{1}{|c|}{ Name } & \multicolumn{1}{c|}{ Description } \\
\hline \multirow{4}{*}{ Feature type } & MaritimeCasualtyInformation & $\begin{array}{l}\text { Common information related } \\
\text { maritime casualty }\end{array}$ \\
\cline { 2 - 3 } & Collision & Collision information \\
\cline { 2 - 3 } & GroundingOrContact & Grounding/Contact information \\
\cline { 2 - 3 } $\begin{array}{c}\text { Information } \\
\text { type }\end{array}$ & Other type of Accidents & $\begin{array}{l}\text { Information about other type of } \\
\text { accidents }\end{array}$ \\
\cline { 2 - 3 } & Consequence & Loss or damage scale information \\
\cline { 2 - 3 } & ShipParticulars & Ship information related casualty \\
\cline { 2 - 3 } & ExternalEnvironmentalData & $\begin{array}{l}\text { Voyage data of ship related } \\
\text { casualty }\end{array}$ \\
\hline \multirow{4}{*}{$\begin{array}{c}\text { Enumeration } \\
\text { type }\end{array}$} & WindForce & $\begin{array}{l}\text { Weather/Environment } \\
\text { information }\end{array}$ \\
\cline { 2 - 3 } & Visibility & Wind status in casualty \\
\cline { 2 - 3 } & NaturalLight & Visibility status in casualty \\
\cline { 2 - 3 } & TypeOfIce & Ice type in casualty \\
\hline
\end{tabular}




\begin{tabular}{|c|c|c|}
\hline & SeaState & Sea status in casualty \\
\hline & TypeOfWeather & Weather status in casualty \\
\hline & CollisionDetailType & Sub-category of collision \\
\hline & Grounding_ContactType & $\begin{array}{l}\text { Sub-category of } \\
\text { grounding/contact }\end{array}$ \\
\hline & AccidentDetailType & Sub-category of other accident \\
\hline & ObjectType & $\begin{array}{l}\text { Object type of grounding/contact } \\
\text { casualty }\end{array}$ \\
\hline & CasualtyEventSeverity & Severity of casualty \\
\hline & BooleanOrUnknown & True, False, Unknown \\
\hline & ShipOperation & Ship operation status in casualty \\
\hline & VDR_S-VDRState & VDR/S-VDR status in casualty \\
\hline \multirow{4}{*}{$\begin{array}{l}\text { Complex } \\
\text { Attribute type }\end{array}$} & SeaIce & Detail information of Ice \\
\hline & OilCargoOrBukerTypeAndQuantity & Type and quantity of oil spill \\
\hline & $\begin{array}{l}\text { ChemicalInBulkPollutionCategory } \\
\text { AndQuantity }\end{array}$ & $\begin{array}{l}\text { Type and quantity of chemical } \\
\text { pollution }\end{array}$ \\
\hline & DangerousGoodsInPackaged & $\begin{array}{l}\text { Type and quantity of dangerous } \\
\text { goods }\end{array}$ \\
\hline
\end{tabular}

Table 5 displays the names and brief descriptions of Feature, Information, Enumeration, and ComplexAttribute types. Detailed information on the 4 types (Attribute, Multiplicity, Data type, Association, etc.) are given in the separate application schema table.

An S-100 based feature catalogue presents the abstraction of reality represented in one or more sets of geographic data as a defined classification of phenomena. The core components of classification in the feature catalogue are the feature type. Features and attributes are bound in a feature catalogue. The definitions of features and attributes are drawn from a feature concept dictionary. A feature catalogue will be available in electronic form (e.g. XML) for any set of geographic data that contains features. A feature catalogue may also comply with the specifications of this component of S-100 independently of any existing set of geographic data. Table 6 provides the 'MaritimeCasualtyInformation' featured according to the S-100 Appendix form. All Feature, Information, Complex Attribute, and Enumeration types have been defined in the same manner.

Table 6. Feature Catalogue Table about 'MaritimeCasualtylnformation' Feature

\begin{tabular}{|c|c|c|c|c|c|}
\hline Item & Name & Description & $\begin{array}{l}\text { Multipl } \\
\text { icity }\end{array}$ & Data type & $\begin{array}{c}\text { Relation } \\
\text { with } \\
\text { feature } \\
\text { class }\end{array}$ \\
\hline $\begin{array}{l}\text { Feature } \\
\text { class }\end{array}$ & $\begin{array}{l}\text { MaritimeCasualty } \\
\text { Information }\end{array}$ & $\begin{array}{l}\text { Feature of } \\
\text { maritime } \\
\text { casualty }\end{array}$ & & & \\
\hline $\begin{array}{l}\text { Attribut } \\
\mathrm{e}\end{array}$ & summaryOfEvent & $\begin{array}{l}\text { Summary of } \\
\text { casualty }\end{array}$ & {$[1]$} & CharString & \\
\hline $\begin{array}{l}\text { Attribut } \\
\mathrm{e}\end{array}$ & dateTime & $\begin{array}{l}\text { Date and time } \\
\text { of casualty }\end{array}$ & {$[1]$} & DateTime & \\
\hline $\begin{array}{l}\text { Attribut } \\
\text { e }\end{array}$ & casualtyEventSeverity & $\begin{array}{l}3 \text { stages into } \\
\text { severity of } \\
\text { casualty }\end{array}$ & {$[1]$} & $\begin{array}{l}\text { CasualtyEventSeve } \\
\text { rity }\end{array}$ & \\
\hline $\begin{array}{l}\text { Attribut } \\
\mathrm{e}\end{array}$ & underPilotage & Being Pilotage & {$[1]$} & $\begin{array}{l}\text { BooleanOrUnknow } \\
\mathrm{n}\end{array}$ & \\
\hline $\begin{array}{l}\text { Attribut } \\
\mathrm{e}\end{array}$ & gmdssUsed & $\begin{array}{l}\text { Using } \\
\text { GMDSS }\end{array}$ & [1] & $\begin{array}{l}\text { BooleanOrUnknow } \\
\mathrm{n}\end{array}$ & \\
\hline Attribut & life- & Being life- & {$[1]$} & BooleanOrUnknow & \\
\hline
\end{tabular}




\begin{tabular}{|c|c|c|c|c|c|}
\hline $\mathrm{e}$ & savingApplianceUsed & saving facility & & $\mathrm{n}$ & \\
\hline $\begin{array}{l}\text { Attribut } \\
\mathrm{e}\end{array}$ & shipAbandoned & $\begin{array}{l}\text { Being } \\
\text { abandoned } \\
\text { ship }\end{array}$ & {$[1]$} & $\begin{array}{l}\text { BooleanOrUnknow } \\
\mathrm{n}\end{array}$ & \\
\hline $\begin{array}{l}\text { Attribut } \\
\text { e }\end{array}$ & vdr_s-vdrState & $\begin{array}{l}\text { Operation } \\
\text { status of } \\
\text { VDR/S-VDR }\end{array}$ & {$[1]$} & VDR_S-VDRState & \\
\hline $\begin{array}{l}\text { Informa } \\
\text { tion } \\
\text { type } \\
\text { class }\end{array}$ & CasualtyConseqeunce & $\begin{array}{l}\text { Damage scale } \\
\text { of casualty }\end{array}$ & {$[0 . .1]$} & Cosequence & $\begin{array}{l}\text { Aggereg } \\
\text { ation }\end{array}$ \\
\hline $\begin{array}{l}\text { Informa } \\
\text { tion } \\
\text { type } \\
\text { class }\end{array}$ & $\begin{array}{l}\text { RelatedShipInformatio } \\
\mathrm{n}\end{array}$ & $\begin{array}{l}\text { Detail } \\
\text { information of } \\
\text { casualty } \\
\text { related ship }\end{array}$ & {$[1 . . *]$} & ShipParticulars & $\begin{array}{l}\text { Aggereg } \\
\text { ation }\end{array}$ \\
\hline $\begin{array}{l}\text { Informa } \\
\text { tion } \\
\text { type } \\
\text { class } \\
\end{array}$ & VoyageInformation & $\begin{array}{l}\text { Voyage } \\
\text { information of } \\
\text { defendant ship }\end{array}$ & {$[1 . . *]$} & VoyageData & $\begin{array}{l}\text { Aggereg } \\
\text { ation }\end{array}$ \\
\hline $\begin{array}{l}\text { Informa } \\
\text { tion } \\
\text { type } \\
\text { class }\end{array}$ & $\begin{array}{l}\text { CasualtyEnvironmetall } \\
\text { nformation }\end{array}$ & $\begin{array}{l}\text { Weather/Envir } \\
\text { onment } \\
\text { information in } \\
\text { casualty }\end{array}$ & {$[0 . .1]$} & $\begin{array}{l}\text { ExternalEnvirionm } \\
\text { entalData }\end{array}$ & $\begin{array}{l}\text { Aggereg } \\
\text { ation }\end{array}$ \\
\hline
\end{tabular}

The Enterprise Architect (EA) tool of Sparx systems supports data modeling work [7]. The EA tool provides some useful function related UML such as elicitation XML schema from UML diagram and generation GML application schema [8]. Figure 6 shows the GML application schema generated by EA tool.

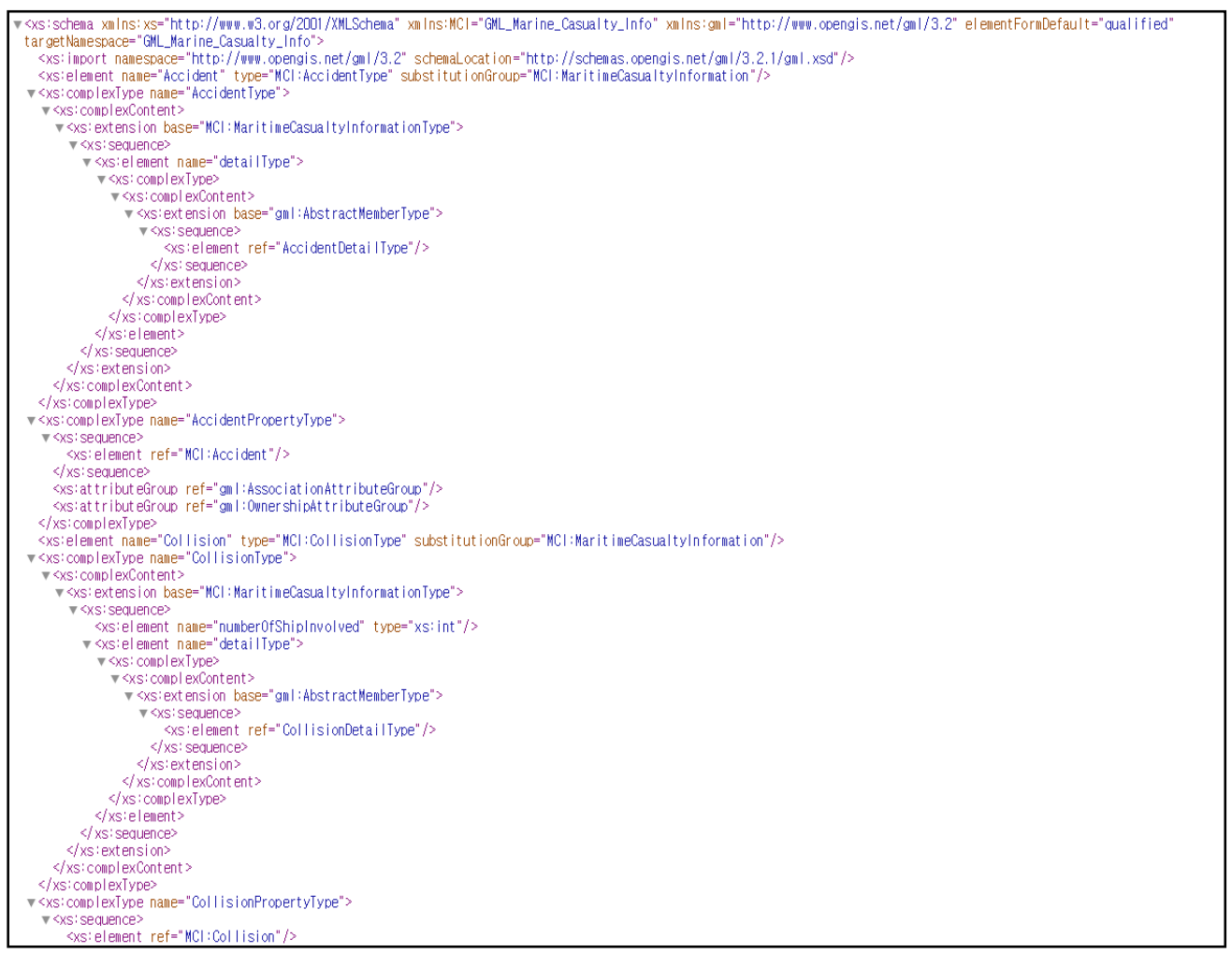

Figure 6. GML Application Schema 


\section{Conclusion \& Future Research}

Digitization has been performed more than once before in the marine area for the safety of navigation in ocean as introducing the e-Navigation Common data structures are required to be able to provide service to users appropriately as delivering lots of data between ship to ship, ship to shore, shore to shore and shore to ship. IMO decided to adopt the S-100 standard developed by IHO as the CMDS and relevant product specifications. This paper provides data modeling of maritime casualty, which can be suggested as a part of S-100 based product specification to IHO. The next step of this work will be an implementation of the data model including features, information, and attribute types.

\section{Acknowledgments}

This Research is the outcome of the 'The New Product/Technology Development Projects with a Purchase Condition' project sponsored by the Small and Medium Business Administration (2015-2017) and 'the Development of common guideline for SW reliability and functional safety' funded by SW Engineering center of NIPA(National IT Industry Promotion Agency), ROK(2016).

This paper is a revised and expanded version of a paper entitled, "Extention of eNavigation Common Data Structure for Marine Casualty Display as a Nautical Warnings Application”, presented at MITA 2016, Luang Prabang, Lao PDR, July 4-6.

\section{References}

[1] MSC/81/23/10, "Development of an E-Navigation strategy", International Maritime Organization, IMO, (2006).

[2] D. Park, H. C. Kwon and S. Park, "Design and Implementation of Feature Catalogue Builder based on the S-100 Standard", journal of Korea Information Processing Society, vol. 2, no. 8, (2013), pp. 571-578.

[3] S100WG TSM3 5.1, "Interoperability of S-100 Product Specifications", International Hydrographic Organization, IHO, (2016).

[4] K. I. Lee, M. S. Song and B. T. Jang, "International Standards and Technology for E-Navigation and Maritime IoT", Electronics and Telecommunications Trends, vol. 29, no. 5, (2014), pp. 18-29.

[5] S. Lee, H. Kim and H. Y. Kim, "Web-based Implementation for Maritime Casualty Information on Google Map", International Journal of Multimedia and Ubiquitous Engineering, vol. 9, no. 6, (2014), pp. 263-268.

[6] MSC-MEPC.3/Circ.4/Rev.1, “CASUALTY-RELATED MATTERS REPORTS ON MARINE CASUALTIES AND INCIDENTS”, International Maritime Organization, IMO, (2014).

[7] Sparx Systems, Author, "Sparx systems Enterprise Architect - User guide Series: UML Models", Sparx systems, (2016)

[8] Sparx Systems, Author, "Sparx systems Enterprise Architect - User guide Series: Geospatial Models", Sparx systems, (2016).

[9] H. Kim, C. H. Mun and S. Lee, "Extension of e-Navigation Common Data Structure for Marine Casualty Display as a Nautical Warnings Application", Proceedings of the 12th International Conference on Multimedia Information Technology and Applications, Luang Prabang, Lao PDR, (2016).

\section{Authors}

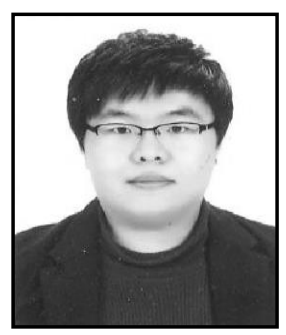

Hyoseung Kim, He is studying in Ph.D. course at Korea Maritime and Ocean University. He is interested in web-services and software developments related to maritime safety information. $\mathrm{He}$ is also interested in studying the S-100 standard and related computing techniques. 


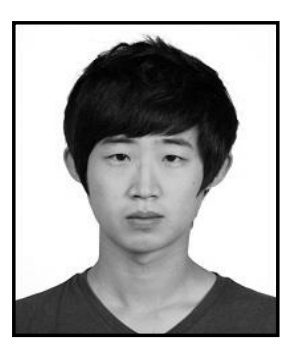

ChangHo Mun, $\mathrm{He}$ is studying in master's degree at Korea Maritime and Ocean University. $\mathrm{He}$ is interested in software developments related to maritime safety information. He is also interested in studying the S-100 standard and related computing techniques.

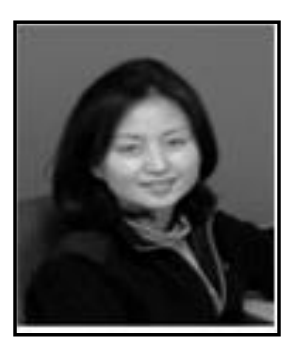

Seojeong Lee, She is Professor at Korea Maritime and Ocean University. She is interested in software development and software quality issues related to vessel navigation and communication systems as well as shore side system. The theme of her Ph.D. dissertation from Sookmyung Women's University in 1998 was a software development methodology. Since joined to Korea Maritime and Ocean University in 2005, she has led the development of the SQA and HCD guideline for e-navigation (IMO MSC Circ.1512) as a representative of Republic of Korea. She is a member of several academic societies in computer engineering and participate to a IMO's sub-committee of NCSR. Professor / Ph.D. IT Engineering Division, Korea Maritime and Ocean University Tajongro 727, Youngdo-gu, Busan, 606-791, Republic of Korea. Email : sjlee@kmou.ac.kr. 